\title{
Air pollution and poverty: Does the sword cut both ways?
}

\section{F W Lipfert}

\section{Poor people may be more susceptible, but poverty also fosters increased pollution}

$\mathrm{T}$ his issue of the journal includes three papers that touch on relations among socioeconomic status (SES), health, and air quality. Jerrett et al considered whether SES differentials in Hamilton, Ontario, modify the temporal relations between daily mortality and either coefficient of haze $(\mathrm{COH})$ or $\mathrm{SO}_{2} .{ }^{1}$ Martins et al did a similar analysis with respect to $\mathrm{PM}_{10}$ in Sao Paulo, Brazil. ${ }^{2}$ The third paper, by Gouveia et al, also involved Sao Paulo but examined cross sectional relations between several pollutants and infant birth weight. ${ }^{3}$ As such, it involves SES factors only implicitly, by virtue of the trends seen by Martins et $a l^{2}$ that link levels of $\mathrm{PM}_{10}$ in Sao Paulo with residence in slums and other SES indicators. Inequitable distribution of environmental impacts within a city or region may raise issues of "environmental justice", * but it may also be possible to get additional insights into the implied health relations by probing a little deeper into the nature and origins of such differential impacts.

Most time series studies are based on entire cities and spatially averaged air quality, in order to maximise statistical power and to preclude the necessity of assigning individual deaths to specific air quality monitors. Time series studies avoid SES confounding by design, as those factors do not vary on a daily basis. However, many air pollutants tend to vary in concert, especially those that are co-emitted by common sources, thus making it difficult to identify the most probable causal agent. Cross sectional studies may have less co-pollutant collinearity, but can suffer from SES confounding to the extent that SES may tend to decrease with residential

*The US Environmental Protection Agency (EPA) defines environmental justice as follows (condensed from http://www.epa.gov/compliance/ environmentaljustice/index.html): the fair treat ment of all people with respect to environmental regulations and policies. Fair treatment means that no group should bear a disproportionate share of negative environmental consequences resulting from industrial, municipal, or commercial operations. proximity to major pollution sources. All of these issues are in play among these three studies.

Jerrett et al matched daily deaths in five zones of Hamilton, Ontario with $\mathrm{COH}$ and $\mathrm{SO}_{2}$ data from each of the five available monitoring stations. ${ }^{1}$ Total deaths were about the same in all five of the unequally sized zones. They then examined the relations between these mortality responses and each of 12 potential effect modifiers that were based on zone-wide averages (making this an "ecological" study). Although a random effects model showed that the heterogeneity among zonal risk estimates was not significant, the authors concluded that manufacturing employment and educational attainment were significant modifiers of the effect of $\mathrm{COH}$ on daily mortality. They proposed three possible rationales for this finding: additional pollutant exposures from the workplace, reduced measurement error because of less mobility, or surrogate effects of material deprivation in general. Interestingly, household income showed no tendency to modify the time series relations, and the mean distance to hospital appeared to rank third (after education), suggesting the importance of access to medical care in these acute situations. The risk estimates were not associated with the mean ambient $\mathrm{COH}$ level, even though $\mathrm{COH}$ was moderately correlated with both poverty and unemployment. The basic problem here is that it is not possible to identify which of the several different rationales might be worthy of public health scrutiny, based on only five observations. An obvious remedy is to use individual rather than aggregate data, including estimates of exposure.

Martins et al defined six subregions of Sao Paulo, each with a radius of $2 \mathrm{~km}$ but differing greatly in population. ${ }^{2}$ One region had four air quality monitors; the others, only one. $\mathrm{PM}_{10}$ was the only pollutant considered; mean values ranged from about 40 to $70 \mu \mathrm{g} / \mathrm{m}^{3}$ and appeared to be correlated with both slum housing and respiratory mortality response rate. Based on the data taken from the paper, an effect modification regression on both slum residency and the $\mathrm{PM}_{10}$ level appeared to be slightly superior to one based on slum residency alone. This outcome may be relevant to the widespread occurrence in Sao Paulo of levels above the former US $\mathrm{PM}_{10}$ annual standard. From that regression, it appears that the $\mathrm{PM}_{10}$ exposure level is just as important as socioeconomic conditions, but we have no way of knowing what other pollutant exposures might also be playing a part. For example, $\mathrm{NO}_{2}$ levels in Sao Paulo are about four times those in the US and another study of daily mortality in Sao Paulo showed large effects for CO and $\mathrm{PM}_{10}{ }^{4}$ Comparing this paper with a previous analysis of SES effects in Sao Paulo $^{5}$ that was based on city-wide air quality suggests that local exposure (and thus individual) gradients could be very important.

Gouveia et al studied the relations between birth weights of Sao Paulo infants and first, second, and third trimester exposures to $\mathrm{PM}_{10}, \mathrm{CO}, \mathrm{SO}_{2}$, $\mathrm{NO}_{2}$, and $\mathrm{O}_{3} \cdot{ }^{3}$ A suite of potentially confounding variables was considered, but smoking, alcohol use, and poverty status were not among them. In terms of changes in mean birth weight, only first trimester exposures showed consistent negative effects, for all five pollutants. The decrements associated with mean levels of $\mathrm{PM}_{10}, \mathrm{CO}, \mathrm{NO}_{2}$, were in the range 83-86 g; effects of $\mathrm{SO}_{2}$ and $\mathrm{O}_{3}$ were smaller and not significant. However, similar findings were not obtained with logistic regressions for the odds of low birth weight (LBW). For example, a birth weight decrement of $85 \mathrm{~g}$ applied to the entire population should have created a relative risk for LBW of about 1.5 (assuming a normal distribution), but the values reported were much smaller and $\mathrm{SO}_{2}$ even showed significant beneficial effects in the first trimester. Furthermore, the actual fraction of LBW in Sao Paulo $(5 \%)$ is less than then typically seen in the United States $(7.7 \%)$, even though the mean US birth weight is $200 \mathrm{~g}$ higher. ${ }^{6}$ Furthermore, a study of air quality and birth weight in the north eastern US that controlled for smoking and alcohol found that CO showed the most consistent effects on LBW, with an OR of 1.3 for a 1 ppm increment in the third semester, ${ }^{7}$ and a similar study in northern Nevada also found a negative association between third trimester $\mathrm{PM}_{10}$ and mean birth weight but not with the fraction of LBW. ${ }^{8}$ These discrepancies make it difficult to accept the Sao Paulo birth weight associations as causal.

Differential environmental impacts may result from at least two important 
pathways: differential exposures, or differential susceptibilities. Environmental justice refers primarily to exposures; note that the official definition* does not pertain to excessive vehicular or domestic emissions that may be an inevitable result of being poor in an urban setting. Additional exposure differentials may result from differences in housing quality, in terms of air exchange rates and the presence of indoor pollution sources. An important point to be made here is that, to the extent that outdoor air quality may be implicated, the culprits are much more likely to be local primary pollutants like $\mathrm{CO}$ or $\mathrm{SO}_{2}$ than the more widespread secondary pollutants like $\mathrm{PM}_{2.5}$ or $\mathrm{O}_{3}$. Indeed, studies in Southern California show that wealthy suburban communities are more likely to experience consistently higher ozone levels than central city locations having higher densities of $\mathrm{NO}_{\mathrm{x}}$ emissions. ${ }^{9}$ Finally, a residence that is transparent to outdoor air pollution will also be transparent to extreme weather effects. For example, studies of the 1995 major heat wave in Chicago found that lack of access to air conditioning was a major risk factor in heat related deaths. ${ }^{10}$

In addition to exacerbating exposures, poverty status may also involve increased susceptibility to environmental challenges by virtue of differences in underlying health status and access to medical care. For example, Gwynn and Thurston found that higher hospital admission-pollution risks were seen for Medicaid (poverty) patients than for those who were privately insured, ${ }^{11}$ and Janssen et al reported that access to residential central air conditioning appeared to reduce the effect of $\mathrm{PM}_{10}$ on daily mortality in 14 US cities. ${ }^{12}$ However, Zanobetti and Schwartz reported that mortality-pollution effect modifications from SES were "modest" compared with those due to medical conditions, ${ }^{13}$ and Tolbert et al found that poverty status (as indicated by Medicaid insurance) increased the risk of children's emergency room treatment for asthma although poverty did not significantly affect the role of air pollution in that regard. ${ }^{14}$ These issues are especially important for time series studies of the elderly population, which imply that the affected victims have succumbed on a particular day as a result of exposure to outdoor air quality no worse (and often better) than what has been experienced many times before. This paradox can only be rationalised in terms of the juxtaposition of a moderate environmental insult with an impaired ability to maintain homeostasis. ${ }^{15}$

Considering all of these factors, the real villain here is seen to be poverty in itself and the socioeconomic conditions that produce it. In many industrialised nations (including the United States) poverty leads to substandard medical care, substandard nutrition, substandard housing, and reliance on inefficient and excessively polluting vehicles and heating and cooking appliances. It has been estimated that as few as $10 \%$ of the vehicles on the road may produce most of the vehicular pollution; however, taking these vehicles off the road would impose intolerable costs on those least able to pay. To make matters even worse, in terms of disposable income, the poor will bear disproportionate shares of the economic burdens of any cost ineffective environmental regulations that unduly increase prices of housing, fuels, vehicles, or appliances. True environmental justice requires the costs imposed by environmental regulations to match their benefits for everyone, not just for society as a whole.

J Epidemiol Community Health 2004;58:2-3

Correspondence to: F W Lipfert, Independent Consultant, 23 Carll Court, Northport, New York 00768, USA; flipfert@suffolk.lib.ny.us

\section{REFERENCES}

1 Jerrett M, Burnett RT, Brook J, et al. Do socioeconomic characteristics modify the short term association between air pollution and mortality? Evidence from a zonal time series in Hamilton, Canada. J Epidemiol Community Health 2004;58:31-40.

2 Martins MCH, Fatgati FL, Vespoli TC, et al. Influence of socioeconomic conditions on air pollution adverse health effects in elderly people: an analysis of six regions in São Paulo, Brazil. $J$ Epidemiol Community Health 2004;58:41-6.

3 Gouveia N, Bremner SA, Novaes HMD. Association between ambient air pollution and birth weight in São Paulo, Brazil. J Epidemiol Community Health 2004;58:11-17.

4 Saldiva PNN, Pope CA III, Schwartz J, et al. Air pollution and mortality in elderly people: a timeseries study in São Paulo, Brazil. Arch Environ Health 1995;50:159-63.

5 Gouveia N, Fletcher T. Time series analysis of air pollution and mortality effects by cause, age, and socioeconomic status. J Epidemiol Community Health 2000;54:750-5.

6 Lipfert FW, Zhang J, Wyzga RE. Infant mortality and air pollution: a comprehensive analysis of U.S. data for 1990. J Air Waste Mgmt Assoc 2000;50:1350-66.

7 Maisonet M, Busdh TJ, Correa A, et al. Relation between ambient air pollution and low birth weight in the northeastern United States. Environ Health Perspect 2001;109(suppl 3):351-6.

8 Chen L, Yang W, Jennison BL, et al. Air pollution and birth weight in northern Nevada. Inhal Toxicol 2002;14:141-57.

9 McConnell R, Avol E, Thomas D, et al. Air pollution and bronchitic symptoms in Southern California children with asthma. Environ Health Perspect 1999; 107:7757-60.

10 Semenza JC, Rubin CH, Falter KH. Heat-related deaths during the July 1995 heat wave in Chicago. N Engl J Med 1996;335:84-90.

11 Gwynn RC, Thurston GD. The burden of air pollution: impacts among racial minorities. Environ Health Perspect 2001; 109(suppl 4):501-6.

12 Janssen NA, Schwartz J, Zanobetti A, et al. Air conditioning and source-specific particles as modifers of the effect of $\mathrm{PM}_{10}$ on hospital admissions for heart and lung disease. Environ Health Perspect 2002;1 10:43-9.

13 Zanobetti A, Schwartz J. Race, gender and social status as modifiers of the effects of $\mathrm{PM}_{10}$ on mortality. J Occup Environ Med 2000:42:468-74.

14 Tolbert P, Mulholland JA, Maclntosh DL, et al. Air quality and pediatric emergency room visits for asthma in Atlanta, Georgia. Am J Epidemiol 2000;151:798-810.

15 Frank R, Tankersley C. Air pollution and daily mortality: a hypothesis concerning the role of impaired homeostasis. Environ Health Perspect 2002;110:61-5.

\section{Urban air pollution, health, and equity}

\section{J M Samet, R H White}

\section{Air pollution and equity}

O ver the past decade, an ever ncreasing number of epidemiological studies have linked urban air pollution, particularly particulate matter, to increased risk for morbidity and mortality. ${ }^{2}{ }^{2}$ These new findings have led to revised air pollution standards for the United States and they will probably have similar consequences in other countries around the world. This new evidence on adverse health effects of air pollution has also motivated research to identify those groups within the population who may be at increased risk from exposure, for example: infants, persons with chronic heart and lung disease, and the elderly population. ${ }^{3}$ This issue of the journal includes three papers that address socioeconomic status and vulnerability to air pollution.

This is not a new topic for scientific investigation or for public health concern. The environmental justice move- 
ment began more than two decades ago in the United States, originally related to the locating of toxic waste landfills in minority communities. ${ }^{4}$ More recently, urban air pollution has surfaced as a significant international environmental justice concern because of the large concentration of minority and low income residents living in urban environments with unhealthful air quality. ${ }^{5}$ These persons often have unhealthy housing and significant exposures to indoor air pollution as well.

Adding to the public health concern regarding the disproportionate exposure of minority and low income populations to high levels of urban air pollution is the recognition that these groups often have higher prevalence rates of diseases such as asthma that are adversely affected by air pollution. Recognition of this disparity in exposures to environmental contaminants, and the need to tackle the potential public health consequences of these disproportionate exposures, was embodied in US national policy through a 1994 Presidential Executive Order $^{6}$ and in Europe in 2001 through the World Health Organisation. $^{7}$

Understanding the role of socioeconomic status as a component of susceptibility to the adverse health effects of air pollution is essential to the process of setting ambient air quality standards and implementing programmes to achieve these standards. In the United States, ambient air quality standards are required to be set under the Clean Air Act at a level sufficient to protect the health of "sensitive groups." Internationally, the WHO Regional Office for Europe has developed air quality guidelines that explicitly recognise the need to consider that subpopulations may be at considerably increased risk of suffering adverse health effects ${ }^{8}$ and therefore must be taken into account in the risk management process. Historically, sensitive groups have been identified on the basis of preexisting health status (for example, people with asthma), physiological development (for example, children), or level of response to pollution (for example, ozone "responders"). In this context, susceptibility can be defined by host factors such as an increased responsiveness to a given dose of air pollution or the prevalence of underlying disease, as well as by exposures to other environmental factors increasing risk for the same outcomes, for example, indoor air pollutants. ${ }^{9}$

The papers in this issue of the journal illustrate some approaches taken by epidemiological researchers to assessing vulnerability to air pollution. In addressing the question of whether persons having lower socioeconomic status are at greater risk from air pollution, epidemiologists test whether the risk estimated for air pollution (or a specific pollutant) varies across strata of socioeconomic status; such variation is referred to as effect modification. Gaining insight into modification of the effect of air pollution on health by socioeconomic status poses several methodological challenges. Firstly, socioeconomic status indicators are only surrogates for more proximal factors that determine health status and potential vulnerability to air pollution. These factors might include nutritional status and prevalence rates of chronic heart and lung diseases, for example. The finding of effect modification by socioeconomic status should trigger further research to better understand the intervening factors. Secondly, some correlates of socioeconomic status may be confounding the relation between air pollution and health. Disentangling complex causal pathways may not be possible, depending on the richness of the data available on relevant correlates of socioeconomic status. Thirdly, estimates of the extent of effect modification are notoriously imprecise, so that sample size may prove a barrier to gaining a picture of variation of the effect of air pollution by socioeconomic status.

Two of the papers in this issue assess socioeconomic status as a modifier by exploring variation of the effect of air pollution across regions within two cities: the city of Hamilton, Canada, ${ }^{10}$ and São Paulo, Brazil. ${ }^{11}$ Both investigative groups followed a similar approach: stratifying the urban region into areas defined by proximity to monitoring stations, developing ecological measures of socioeconomic status for the zones, and testing for variation in the effect of air pollution measures among the zones. Both locations had sufficient spatial variation of socioeconomic status and air pollution to test for effect modification. Despite the substantial differences between these locations, the findings of the two studies were similar in showing greater risk in areas having a predominantly lower socioeconomic status population.

The third paper addresses ambient air pollution and birth weight in São Paulo. ${ }^{12}$ In this analysis, air pollution exposures during each trimester were estimated and their associations with birth weight examined in multivariable models that took several factors, including maternal age, maternal education, and number of prenatal visits into account. A reduction of birth weight with estimated first trimester exposures to particulate matter and carbon mon- oxide was found. This finding adds to a growing literature on reproductive outcomes and urban air pollution. ${ }^{13}{ }^{14}$ Notably, in this study, maternal education, a socioeconomic status measure, was treated as a potential confounding factor and included in the multivariable model. Effect modification was not explored.

What have we learned from these new studies? Firstly, they confirm a number of previous reports with similar findings in both time series studies of acute events ${ }^{2}$ and in longer term cohort studies of mortality. ${ }^{15}$ Secondly, the authors' thoughtful discussions reemphasise the need for cautious interpretation of findings on effect modification, given the range of methodological considerations affecting the results. Thirdly, research on socioeconomic status and the effect of air pollution might be improved by harmonisation of methods and pooled analyses so that differences among studies might be better understood. Clearly, socioeconomic measures have differing correlates across populations and the development of data on the most relevant correlates would be informative. A pooled analysis of mortality data from North America and Europe will soon be underway that will provide an opportunity to assess the role of effect modification across a broad range of cities.

The findings of these and other studies are beginning to provide a coherent and not surprising picture: persons having lesser socioeconomic status seem to be at increased risk from urban air pollution. Further research on this topic is warranted but studies need to extend beyond empiric exploration of effect modification to explore the underlying causal pathways. Hierarchical designs will be needed that explore the relevant individual level correlates of socioeconomic status; personal exposure assessments for key air pollutants should also be incorporated to better characterise exposure by socioeconomic status. Relevant examples include Diez Roux, ${ }^{16}$ and research methods are available for this purpose. ${ }^{17}$

\section{J Epidemiol Community Health 2004;58:3-5}

\section{Authors' affiliations \\ J M Samet, R H White, Johns Hopkins Bloomberg School of Public Health, Department of Epidemiology, the Risk Sciences and Public Policy Institute, Baltimore, USA}

Correspondence to: Professor J M. Samet, Johns Hopkins Bloomberg School of Public Health, $615 \mathrm{~N}$ Wolfe Street, Baltimore, MD, 21205, USA; jsamet@ihsph.edu 


\section{REFERENCES}

1 Pope CA, III, Dockery DW. Epidemiology of particle effects. In: Holgate ST, Samet JM, Koren HS, et al. Air pollution and health. San Diego: Academic Press, 1999:673-705.

2 US Environmental Protection Agency (EPA). National Center for Environmental Assessment. Air quality criteria for particulate matter. Research Triangle Park, NC: US Environmental Protection Agency, 2002.

3 National Research Council (NRC), Committee on Research Priorities for Airborne Particulate Matter. Research priorities for airborne particulate matter: no 1. Immediate priorities and a long-range research portfolio. Washington, DC: National Academy Press, 1998.

4 US General Accounting Office. Siting of hazardous waste landfills and their correlation with racial and economic status of surrounding communities. Washington, DC: US Government Printing Office, 1983.

5 World Health Organisation. Environmental health-for the rich or for all? WHO Bulletin. Geneva: WHO, 2001
6 White House Office of the President. Executive order 12898: federal actions to address environmental justice in minority populations and low-income populations. 1994. http://www.epa/ fedsite/e012898.htm (accessed 31 Oct 2003).

7 World Health Organisation, Regional Committee for Europe. Poverty and health-evidence and action in the WHO's European region, EUR/ RC51/8; EUR/RC51/Conf.Doc./6. Geneva: WHO, 2001

8 World Health Organisation, Regional Office for Europe. Air quality guidelines for Europe,, No 91 WHO Regional Publications, European series. Geneva: WHO, 2000

9 American Lung Association. Urban air pollution and health inequities: a workshop report. Environ Health Perspect 2001;109(suppl 3):357-74.

10 Jerrett $M$, Burnett RT, Brook J, et al. Do socioeconomic characteristics modify the short term association between air pollution and mortality? Evidence from a zonal time series in Hamilton, Canada. J Epidemiol Community Health 2004;58:31-40

11 Martins MCH, Fatgati FL, Vespoli TC, et al Influence of socioeconomic conditions on air pollution adverse health effects in elderly people: an analysis of six regions in São Paulo, Brazil. $J$ Epidemiol Community Health 2004;58:41-6.

12 Gouveia N, Bremner SA, Novaes HMD Association between ambient air pollution and birth weight in São Paulo, Brazil. J Epidemiol Community Health 2004;58:11-17.

13 Ritz B, Yu F, Fruin S, Chapa G, et al. Ambient air pollution and risk of birth defects in Southern California. Am J Epidemiol 2002;155: 17-25.

14 Woodruff TJ, Grillo J, Schoendorf KC. The relationship between selected causes of postneonatal infant mortality and particulate air pollution in the United States. Environ Health Perspect 1997; 105:608-12.

15 Krewski D, Burnett RT, Goldberg MS, et al. Reanalysis of the Harvard Six Cities Study and the American Cancer Society Study of particulate air pollution and mortality. Investigators' reports parts I and II. Cambridge, MA: Health Effects Institute, 2000.

16 Diez Roux AV. Investigating neighborhood and area effects on health. Am J Public Health 2001:91:1783-9.

17 Diez-Roux AV. Multilevel analysis in public health research. Annu Rev Public Health 2000;21:171-92.

\section{APHORISM OF THE MONTH}

\section{On the Times, Edwin Chadwick, and the nanny state (I paraphrase)}

$\mathrm{T}$ he London Times is said to have claimed that they would prefer to take their chance with the cholera than be bullied into health by Mr Chadwick. The notion of the "nanny state" clearly has a long pedigree. The argument rumbled on in Europe throughout the 19th century about the appropriate role for the state: minimalist, only concerned with property rights, or interventionist on behalf of social justice and a phenomenon called society, protector of the weak, the poor, the young, the aged and infirm, giving voice to the underdog. In the contemporary climate of neo-liberal global economics, the same arguments are current. We accept that individuals have no chance to deal with bioterrorism and outbreaks of SARS or natural disasters, but how much more chance do they have when faced with the concerted efforts of commercial outfits whose sole aim is to maximise the consumption of tobacco, alcohol, junk food or couch-potato promoting motorcars. Where would Edwin Chadwick stand today on these issues? It's not difficult to guess what the London Times would have to say. 